J. Dairy Sci. 99:9703-9715

http://dx.doi.org/10.3168/jds.2016-11007

(C) American Dairy Science Association ${ }^{\circledR}, 2016$.

\title{
Changes in the intestinal bacterial community, short-chain fatty acid profile, and intestinal development of preweaned Holstein calves. 2. Effects of gastrointestinal site and age ${ }^{1}$
}

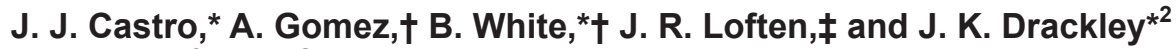 \\ *Department of Animal Sciences, and \\ †Institute for Genomic Biology, University of Illinois, Urbana 61801 \\ ¥Milk Specialties Global Animal Nutrition, Eden Prairie, MN 55344
}

\section{ABSTRACT}

The objective of this work was to assess the effects of age and gastrointestinal location (rumen vs. colon) on bacterial community diversity and composition, as well as short-chain fatty acid profiles of preruminant male Holstein calves on an intensive milk replacer feeding program. Thirty-two calves were fed at $2 \%$ of their body weight (dry matter basis) from d 10 until harvest. Sixteen calves were euthanized at 2 wk and another 16 at $4 \mathrm{wk}$ of age to collect digesta samples from the rumen and colon. The rumen and colon bacterial communities of preruminant calves showed a similar degree of diversity (i.e., Shannon index) whereas composition differed considerably. The colonic bacterial population was characterized by dominance of lactic acid bacteria such as Lactobacillus, Streptococcus, Enterococcus, and Bifidobacterium. In addition, colonic short-chain fatty acid and lactic acid concentrations were between 50 and $850 \%$ higher than in the rumen, indicating greater fermentative activity in the colon. On the other hand, in the rumen, no genus over-dominated and more variation was present among calves. Because of an active reticular groove and low starter grain intake during the first 1 to $3 \mathrm{wk}$ of life, ruminal fermentation may not contribute to significant metabolizable energy supply until after 4 wk of life in intensively fed calves. Until then, calf hindgut fermentation, characterized by high abundance of lactic acid bacteria along with increased lactate and butyrate concentrations, could be beneficial for intestinal health and survival of the calf during the first weeks of life.

Key words: calf, gut health, pyrosequencing, shortchain fatty acids

\footnotetext{
Received February 8, 2016.

Accepted August 1, 2016.

${ }^{1}$ Supported by Milk Specialties Global (Eden Prairie, MN) and state of Illinois and USDA-CREES funds appropriated to the Illinois Agricultural Experiment Station.

${ }^{2}$ Corresponding author: drackley@illinois.edu
}

\section{INTRODUCTION}

Development of microbial populations in the gastrointestinal (GI) tract of higher animals commences soon after birth (Mackie et al., 1999). Some observations indicate that the rumen anaerobic microbiota quickly attain concentrations as high as $10^{9}$ cells $/ \mathrm{mL}$, thus becoming predominant by d 2 after birth (Stewart et al., 1988). Bacteria that are essential for mature rumen function can be detected as early as $1 \mathrm{~d}$ after birth, long before the rumen is active or even before ingestion of plant material occurs (Jami et al., 2013). Moreover, in calves fed only milk, all major types of rumen microorganisms and a stable wide array of microbial metabolic functions have been identified before introducing solid feed, suggesting that the rumen microbial community of the young bovine may not be rudimentary as long believed (Li et al., 2012).

Once fermentable substrate, especially starch, is consumed by the calf, microbial fermentation develops progressively and the resulting short-chain fatty acids (SCFA) directly stimulate growth and function of the rumen epithelium (Flatt et al., 1958; Sutton et al., 1963b). The SCFA will eventually provide the largest proportion of energetic requirements of the animal (Beever and Mould, 2000), thereby rendering the calf energetically independent from an external milk source, be it cow milk or milk replacer. However, fermentation sufficiency, adequate rumen size, and full absorptive capability are not achieved until after about 4 to $6 \mathrm{wk}$ of age (Davis and Drackley, 1998), and the calf thus relies mostly on milk as a nutrient source for the first 1 to 4 wk of life.

Given that during the preweaning period the diet is largely milk-based, that the reticular groove is fully functional, and that essentially all digestion is performed by the host enzymes, the newborn calf can be considered a nonruminant (Orskov, 1992). Depending on age and feeding rate, among other variables, 5 to $20 \%$ of milk DM consumed passes undigested (Guilloteau et al., 1986; Petit et al., 1989; Montagne et al., 2001; Hill et al., 2010) through the ileum into the ce- 
cum and colon and is likely readily available for colonic fermentation in newborn calves. In contrast, very little milk DM would be expected to enter the rumen for fermentation (Toullec and Guiloteau, 1989). Despite this presumably higher flux of fermentable nutrients into the hindgut of the preruminant calf, little information is available on how early microbial activity can affect hindgut development and health (Oikonomou et al., 2013) as compared with the developing rumen (Warner et al., 1956; Sutton et al., 1963a,b; Warner and Flatt, 1965; Huber, 1969).

Whereas early-colonizing pathogens are autochthonous to the gut ecosystem and can live in harmony with the host, they can become pathogenic under certain circumstances (Mackie et al., 1999). Indeed, organisms such as enterotoxigenic Escherichia coli and Salmonella spp. are responsible for a large proportion of cases of neonatal calf diarrhea (Butler and Clarke, 1994; Izzo et al., 2011), which affects about $25 \%$ of preweaned heifers and accounts for more than $50 \%$ of their annual mortality in the United States (NAHMS, 2010). On the other hand, commensal organisms such as Bifidobacterium and Lactobacillus spp. have been linked to increased resistance to infection and diarrheal disease and stimulation of the mucosal immune system (Macfarlane et al., 2008).

During the preruminant stage, therefore, increased fermentable substrate supply may result in bacterial colonization and fermentation establishment in the hindgut that are comparatively equal to or more relevant than in the foregut for the health and survival of the newborn. The objective of this work was to assess the effect of calf age and GI location (rumen vs. colon) on bacterial diversity, community composition, and SCFA profiles in intensively milk-fed Holstein calves. From this same experiment, a companion manuscript examined the effects of prebiotic supplementation and their dependence on GI location and age (Castro et al., 2016).

\section{MATERIALS AND METHODS}

\section{Animals, Feeding, and Treatment Allotment}

All procedures involving animals were approved by the Institutional Animal Care and Use Committee of the University of Illinois at Urbana-Champaign (protocol \#122109). Thirty-two newborn male Holstein calves were purchased from a sale barn. Upon arrival to the University of Illinois research facilities, calves received an electrolyte solution (Electrolyte System Base plus Add Pack, Land O'Lakes Animal Milk Co., Arden Hills, MN), as well as vaccines and prophylactic antibiotic treatment $[2 \mathrm{~mL}$ BoSe, Shering-Plough, Madison,
NJ; $1 \mathrm{~mL}$ of vitamins A and D; $1.1 \mathrm{~mL}$ of Draxxin, Zoetis, Kalamazoo, MI; $50 \mathrm{~mL}$ of antibody serum (Bovisera), Colorado Serum, Denver, CO; $20 \mathrm{~mL}$ of $\mathrm{C}$ and $\mathrm{D}$ antitoxin, Boehringer Ingelheim, St.Joseph, MO; and $2 \mathrm{~mL}$ INFORCE-3, Zoetis]. Arrival BW and plasma protein concentration ranged from 36.3 to $51.3 \mathrm{~kg}$ and 4.6 to $7.2 \mathrm{mg} / \mathrm{dL}$, respectively. Calves were housed in individual hutches bedded with straw. Milk replacers (Excelerate, Milk Specialties Global Animal Nutrition, Eden Prairie, MN) were fed at a rate of $1.25 \%$ of $\mathrm{BW}$ on a DM basis for the first $2 \mathrm{~d}, 1.5 \%$ of BW until d 10 , and then $2 \%$ of BW through wk 4 . Milk replacer protein was provided by dried whey and whey protein concentrate, whereas milk replacer fat was a proprietary blend of tallow, lard, and coconut oil. As described in the companion manuscript (Castro et al., 2016), 2 different isoenergetic and isonitrogenous milk replacers differing in their mono, di-, and oligosaccharide profiles were used in this experiment, and the results presented herein are adjusted for such effects. Milk replacers contained about $29 \%$ CP, $15 \%$ crude fat, $8 \%$ ash, $1.1 \%$ $\mathrm{Ca}$, and $0.6 \% \mathrm{P}$ (DM basis). To test the effects of milk replacer prebiotic in isolation, no starter grain was offered. Whereas it is obvious that lack of solid feed will affect bacterial community development in both rumen and colon, we believe these experimental conditions would resemble those of newborn calves intensively fed milk, whose solid feed intake is very low during the first few weeks of life even when starter is offered for ad libitum consumption (Sweeney et al., 2010). Free water was available at all times.

\section{Animal Slaughter and Sampling}

Sixteen calves were euthanized at 2 wk and another 16 at 4 wk after arrival to collect digesta samples from the rumen and colon. Average calf BW at 2 and 4 wk of age was 46 and $56 \mathrm{~kg}$, respectively. Calves at each age were selected for slaughter randomly from those animals that were healthy and had not received any antibiotic treatment. On each day of euthanasia, 16 calves were transported in groups of 4 to the Diagnostic Laboratory of the University of Illinois at $0430 \mathrm{~h}$ and kept unfed in the interim. Euthanasia was performed by administering an overdose (85 to $150 \mathrm{mg} / \mathrm{kg}$ of BW) of sodium pentobarbital intravenously. The 4 calves per batch were simultaneously dissected by 4 teams of trained staff; processing took approximately 45 to $60 \mathrm{~min} /$ calf. Processing of the 16 calves took approximately 5 to $6 \mathrm{~h}$ on each day. To account for the effect of waiting time in unfed conditions, each group was assigned a slaughter order number (i.e., 1 to 4 ). Therefore, given that the last meal took place approximately at $1700 \mathrm{~h}$ on the previous day, fasting time extended from the regular 
$12 \mathrm{~h}$ daily (1700 to $0500 \mathrm{~h}$ ) to about 17 to $18 \mathrm{~h}$. The possibility exists that such prolonged fasting affected bacterial populations or intestinal function. Nonetheless, a multivariate statistical test comparing the entire global bacterial community composition among slaughter order groups 1 to 4 failed to reject the null hypothesis of no group difference (data not presented), providing evidence that a short-term fast did not affect the bacterial community structure (Castro et al., 2016).

After death, the thoracic and abdominal cavities were opened. The GI tract was removed and ligated between omasum and abomasum, between abomasum and duodenum, and at the ileo-cecal junction to prevent digesta flow due to manipulation. Then, the forestomachs, small intestine, and large intestine were separated for digesta sample collection.

\section{Bacterial DNA Amplicon Sequencing and Taxonomic Assignment}

Digesta samples from rumen and proximal colon were collected into 5-mL sterile cryovials and snap frozen in liquid nitrogen. Samples were submitted to an external laboratory (Research and Testing Laboratory, Lubbock, TX) for bacterial tag-encoded FLX (Roche, Nutley, NJ) amplicon pyrosequencing.

Total microbial DNA was extracted using a MoBio PowerFecal kit (Mo Bio Laboratories Inc., Carlsbad, $\mathrm{CA}$ ), which has been demonstrated to be a good overall method for DNA extraction from digesta from diverse species (Hart et al., 2015). Sample DNA was quantified using a Nanodrop spectrophotometer (Nyxor Biotech, Paris, France). Upon extraction, the V1-V3 hyper-variable regions of the $16 \mathrm{~S}$ ribosomal DNA gene were amplified by PCR using barcoded primers (i.e., 27Fmod 5'-AGRGTTTGATCMTGGCTCAG-3' and 519Rmodbio 5'-GTNTTACNGCGGCKGCTG-3') and the product sequence determined by bacterial tagencoded FLX (nontitanium chemistry) amplicon pyrosequencing using established procedures (Dowd et al., 2008a,b). Details are reported in the companion paper (Castro et al., 2016).

\section{Digesta SCFA Concentration}

Ruminal and colonic digesta samples were collected and acidified with a $10 \mathrm{~N} \mathrm{HCl}$ solution. Afterward, samples were centrifuged at $15,000 \times g$ for $15 \mathrm{~min}$ at $4^{\circ} \mathrm{C}$; the supernatant was extracted, frozen, and sent to the laboratory of V. Fellner (North Carolina State University, Raleigh) for SCFA analysis by GLC (Varian CP 3380/3800, Agilent Technologies Inc., Santa Clara, CA). Briefly, digesta sample supernatant was injected $(1 \mu \mathrm{L})$ into a column (Nukol fused silica capillary col- umn, $30 \mathrm{~m} \times 0.25 \mathrm{~mm} \times 0.25 \mathrm{~mm}$; Sigma-Aldrich, St. Louis, MO). A flame ionization detector was used to quantify SCFA (Herfel et al., 2013). Details are provided in Castro et al. (2016).

\section{Data Analysis}

Bacterial Community Diversity. The Shannon index was calculated as a proxy for diversity. This index takes into account not only the number of species, but also the abundance evenness among species (Tuomisto, 2010). To account for the lack of independence between samples from rumen and colon from the same calf (i.e., possibly auto-correlated errors), a generalized linear model with a random intercept was fitted to the data to induce a compound symmetry correlation structure among observations from the same calf (Zuur et al., 2009). Penalized quasi-likelihood was used to estimate parameters and standard errors; statistical inference followed guidelines by others (Bolker et al., 2009). Data were analyzed under a gamma distribution, as diversity values are bounded by zero from below.

A log link linear predictor for modeling diversity was specified as

$$
\eta_{i j}=\log \left(\mu_{i j}\right)=\beta_{0}+\beta_{1} \times \operatorname{Site}_{j(i)}+\beta_{2} \times \text { Week }_{i}+\mathrm{b}_{0},
$$

where $\mu_{i j}=$ expected Shannon index value in a given week and GI site, $\beta_{0}=$ intercept, $\beta_{1}=$ regression coefficient for GI site, $\beta_{2}=$ regression coefficient for calf age in weeks, and $b_{0}=$ calf random effects. There was no interaction effect between age and site and thus it was not retained in the model. Calf random effects were assumed to be normally distributed and independent.

To interpret the coefficients of the above linear predictor we took the inverse of the natural logarithm (i.e., the exponential or Euler's number):

$$
\mu_{i j}=e^{\beta_{0}} \times e^{\beta_{1} \times \operatorname{Site}_{j(i)}} \times e^{\beta_{2} \times \text { Week }_{i}} .
$$

From here we estimated the expected diversity value for a particular age by GI site group. The exponentiated intercept $\left(\beta_{0}\right)$ represents diversity at 2 wk of age in colon, the exponentiated coefficient for GI site $\left(\beta_{1}\right)$ is the fold change in rumen with respect to colon, and the exponentiated coefficient for week $\left(\beta_{2}\right)$ is the fold change in wk 4 relative to wk 2 in colon.

Bacterial Community Composition. A BrayCurtis distance matrix that provides a measure of the bacterial community similarity among each pair of samples across ages and GI sites was built. This between-sample distance matrix was used for various multivariate analyses. To visually explore the degree of bacterial composition similarity between samples 
collected at 2 and 4 wk of age from rumen and colon, nonmetric multidimensional scaling (NMDS) was conducted on the above Bray-Curtis distance matrix (Borcard et al., 2011). The NMDS stress measure was always below 0.2 indicating the ordination provided a good fit to the observed community dissimilarities (Borcard et al., 2011).

To statistically test any visually apparent group differences from the NMDS plots, analysis of similarities (ANOSIM; Clarke, 1993) and permutational multivariate analysis of variance (PERMANOVA; Anderson, 2001) were conducted with GI sites nested within age. The ANOSIM statistically tests whether a difference exists between 2 or more groups of sampling units based on the difference of mean distance ranks computed from the Bray-Curtis distance matrix. The ANOSIM statistic $\mathbf{R}$ lies in the range from -1 to 1 . If all replicates within a group are more similar to each other than any replicates from different groups, $\mathrm{R}=1$. The $\mathrm{R}$ statistic approaches 0 as similarities between and within different groups become the same on average. Rarely is $\mathrm{R}$ less than 0 and if so it indicates possible mislabeling of samples as it implies that samples are more similar between than within groups. The statistical significance (i.e., $P$-value) of the observed R statistic is assessed by permutation. The PERMANOVA instead partitions the total sums of squares estimated from the Bray-Curtis distance matrix among sources of variation and uses a permutation test with pseudo- $F$ ratios to compute a $P$-value.

Multivariate homogeneity of variances (Anderson, 2006) was tested by calculating the distance of each sample to the group median (i.e., centroid) in multivariate space and then testing if the average distance among groups was different through parametric ANOVA. Subsequently, to identify which genera contributed most to the observed bacteria compositional differences among groups, similarity percentage analysis (SIMPER; Clarke, 1993) was run separately across weeks of age and GI sites. Due to SIMPER methodological limitations (Warton et al., 2012), some of these results are complemented by univariate tests as appropriate using the generalized linear mixed model framework similar to that described above for the bacterial community diversity data (Bolker et al., 2009; Fitzmaurice et al., 2011). The sequence read counts of each of the most predominant bacterial taxa (i.e., phyla and genera) were thus analyzed in the same fashion as diversity but following a negative binomial distribution to account for counts over-dispersion. Because the total number of sequence reads varies from sample to sample, it was used as an offset variable to express taxa abundance in relative terms (i.e., genus $i$ counts/total number genera counts; Zuur et al., 2009).
Besides the intergroup abundance criteria, it was also of interest to detect the assemblage of organisms that best characterizes a GI site based on their affinity for that niche. Thus, species indicator analysis (INDVAL; Dufrene and Legendre, 1997) was performed. This analysis provides a species indicator index that ranges between 0 and 1 . If a genus is uniquely present in one group of calves and it is present in each individual calf belonging to that group, then the indicator index takes a maximum value of 1 ; whereas if such genus is not exclusive of a given group and is not present in each member of that group, the index approaches 0 (Legendre, 2013). A permutational $P$-value was used to assess statistical significance of the indicator value. The NMDS and ANOSIM were carried out in Primer-E software V.6.0; SIMPER (Clarke and Gorley, 2006), PERMANOVA, and multivariate heterogeneity of variances tests were conducted with the package Vegan (Oksanen et al., 2012); INDVAL was carried out with the package Labdsv (Roberts, 2012); and generalized linear models were performed with the package MASS (Venables and Ripley, 2002) in the open access $\mathrm{R}$ language (version 2.14.0, R Development Core Team, Vienna, Austria).

Intestinal SCFA Concentrations. Colon and rumen SCFA data were analyzed as spatially repeated measures on the same calf. Because only 2 observations were recorded on the same animal, a compound symmetric (i.e., constant covariance) error structure with heterogeneous variances was implemented in PROC MIXED of SAS (ver. 9.3, SAS Institute Inc., Cary, NC).

\section{RESULTS}

\section{Bacterial Community Diversity}

Figure 1 illustrates the data distribution for diversity (i.e., Shannon index). Age by GI site groups appear to be similar. Table 1 displays the regression coefficients describing the effect of age and GI site on diversity. Indeed, the coefficients for age and GI site were not different from zero; therefore, we infer that the number of taxa and their abundance evenness were similar across ages and GI sites.

\section{Bacterial Community Composition}

Phyla Level. Out of 18 phyla identified, 5 of them were found to make up $\sim 98.5 \%$ of the total (Figure 2). Across GI sites and ages, Firmicutes was the most abundant with $70 \%$, followed by Bacteroidetes (12\%), Actinobacteria (8\%), Tenericutes (5\%), and Proteobacteria $(3.5 \%)$. From the phyla data distributions illustrated in Figure 3, it is readily apparent that although Firmicutes was more abundant in colon, Bacteroidetes and Tenericutes were more abundant in rumen. 
Table 1. Regression coefficients for effect of calf age and gastrointestinal site on microbial diversity as estimated by the Shannon index

\begin{tabular}{lcccc}
\hline Parameter & Coefficients $(\beta)$ & SE & $P$-value & $\exp ^{(\beta) 1}$ \\
\hline Intercept & 1.32 & 0.03 & $<0.00001$ & 3.74 \\
Week 4 & 0.036 & 0.04 & 0.34 & 0.44 \\
Rumen & 0.029 & 0.04 & ${ }^{(\text {Intercept })}=$ represents expected value for colon at 2 & wk of age; $\exp ^{(\text {Week }}$ 4) $=$ represents fold change at 4 wk \\
${ }^{1} \exp ^{(\text {(Rumen })}$ & $=$ represents fold change in rumen with respect to colon.
\end{tabular}

Regression coefficients for the statistical assessment of the effects of age and GI site on relative abundance of each phylum are displayed in Table 2. Firmicutes abundance was affected by the calf age and GI site. At $4 \mathrm{wk}$, calves presented 1.36 times the abundance of this phylum compared with calves 2 wk old $(P=0.0022)$. In addition, in agreement with Figure 3, rumen contained only $\sim 0.68$ times the Firmicutes abundance observed in colon $(P=0.0001)$. Also in agreement with Figure 3, we found no effect of age on Bacteroidetes abundance $(P=0.7)$, but this phylum was 5.1 -fold more abundant in rumen than in colon $(P=0.01)$. Actinobacteria abundance was not different between ages $(P=0.08)$ or GI sites $(P=0.15)$. For Tenericutes, both age and GI site affected its abundance. It was found to be more abundant at 2 than at $4 \mathrm{wk}$ of age $(P=0.01)$ and much more abundant (i.e., $\sim 4$ times) in rumen $(P=$ 0.01) than in colon (Figure 3). Proteobacteria also was significantly more abundant in rumen than in colon $(P=0.002)$. Overall, it appears that Firmicutes was more abundant in colon than in rumen, whereas Bacteroidetes, Proteobacteria, and Tenericutes were more abundant in rumen than in colon.

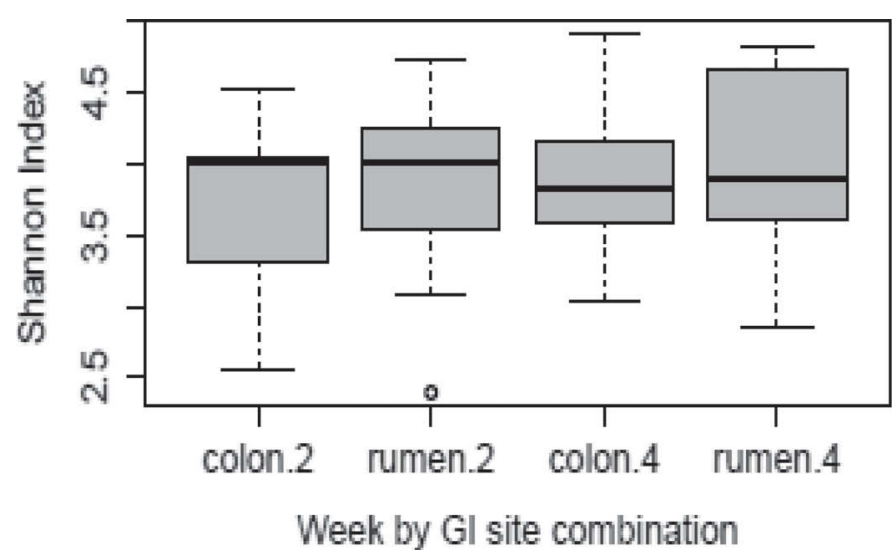

Figure 1. Shannon index diversity measures across gastrointestinal (GI) sites and calf ages. colon. $2=$ colon at $2 \mathrm{wk}$; rumen. $2=$ rumen at $2 \mathrm{wk}$; colon. $4=$ colon at $4 \mathrm{wk}$; rumen. $4=$ rumen at $4 \mathrm{wk}$. Lower and upper most bars are maximum and minimum values, respectively, excluding outliers; upper and lower box sides are 25th and 75th percentiles and the solid horizontal line is the median or 50th percentile.
Genus Level. The NMDS plot in Figure 4a displays the samples belonging to colon and rumen at 2 and 4 wk of age. Whereas rumen samples from 2 and 4 wk appeared to group distinctly from each other, colon samples from 2 and 4 wk of age displayed large overlap, suggesting that the composition of colonic microbiota is more similar at wk 2 and 4 compared with rumen. At the same time, rumen and colon form different clusters (Figure 4a), and when considered across ages (Figure $4 \mathrm{~b})$ we noted a visually evident dissimilarity between ruminal and colonic bacterial communities. When comparing wk 2 and 4 (Figure 4c), only moderate separation of clusters can be appreciated, suggesting that calves at 2 and 4 wk of age share more of their overall bacterial community composition (i.e., they are more similar) than GI sites within calves do.

To statistically test the compositional differences suggested by NMDS plots, PERMANOVA was carried out. The GI site $\left(P=0.001, \mathrm{R}^{2}=24.4 \%\right.$, Figure $\left.4 \mathrm{~b}\right)$, weeks of age $\left(P=0.001, \mathrm{R}^{2}=4.4 \%\right.$, Figure $\left.4 \mathrm{c}\right)$, and their interaction $\left(P=0.006, \mathrm{R}^{2}=4 \%\right.$, Figure $\left.4 \mathrm{a}\right)$ were found to significantly affect and explain approximately $32.8 \%$ of variation in the composition of the bacterial community. The significant interaction between age and GI site indicates that the effect of age depended on the GI site. Indeed, from Figure 4a it is evident that, whereas bacterial populations found at 2 and $4 \mathrm{wk}$ in the colon do not appear to differ greatly, they do differ in the rumen, causing samples from 2 and 4 wk of age to cluster apart clearly.

A multivariate variance homogeneity test was conducted, which indicated that the bacterial community composition in the colon of calves at 4 wk of age was much less variable than that in the rumen at 2 and 4 wk or colon at 2 wk $(P<0.001)$, which reflects the dispersion among ruminal and colonic samples in Figure 4a. Whereas this warns of a violation of the variances homogeneity condition for PERMANOVA, heterogeneity is less of an issue with balanced designs (i.e., same number of samples in each treatment combination), such as the present experiment (Anderson and Walsh, 2013). It does highlight, however, that colonic microbiota was more homogeneous among calves by $4 \mathrm{wk}$ of age than was the ruminal microbiota. 


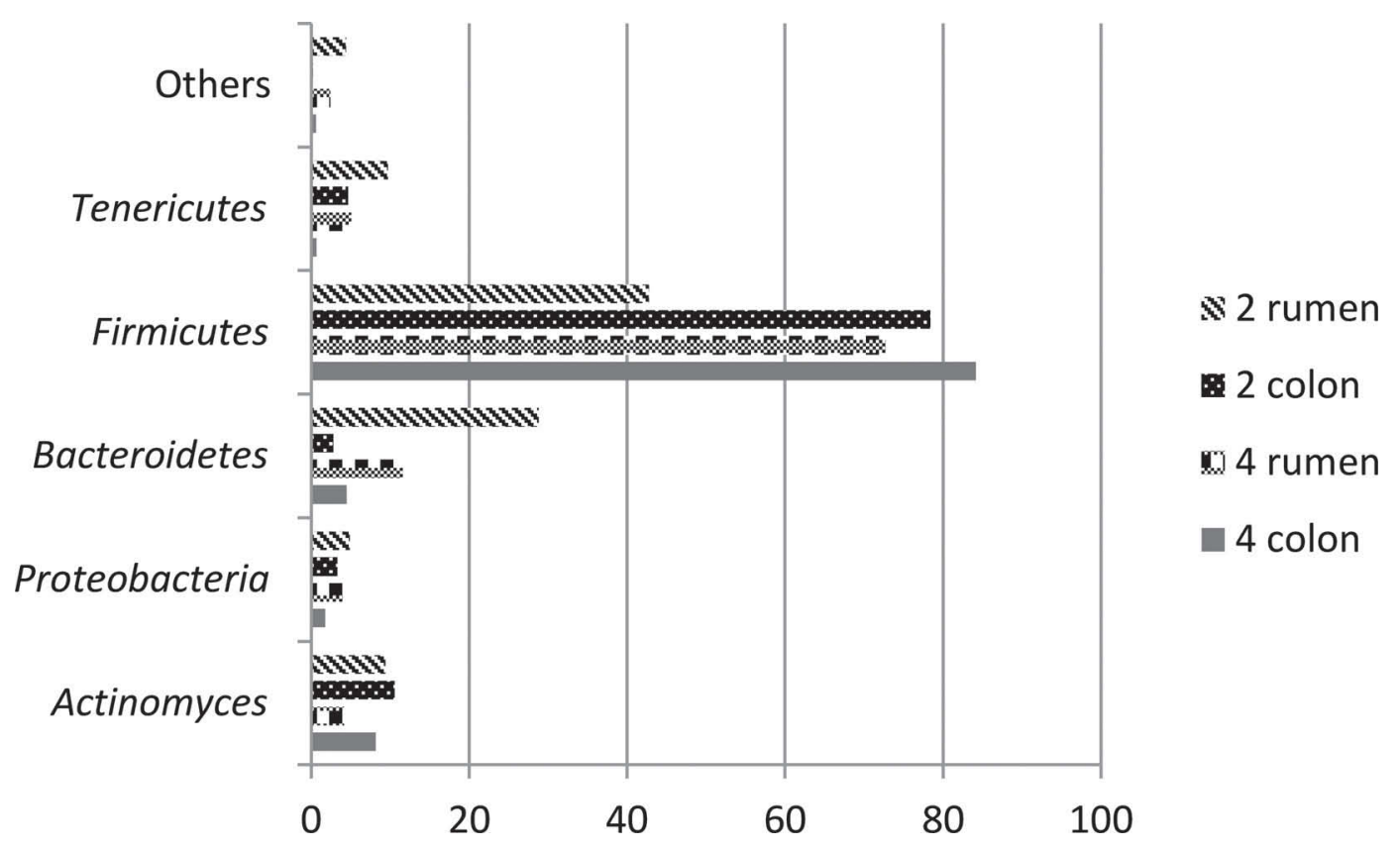

Figure 2. Predominant phyla abundance across calf ages and gastrointestinal sites. 2 rumen $=$ rumen at 2 wk; 2 colon $=$ colon at 2 wk; 4 rumen $=$ rumen at $4 \mathrm{wk} ; 4$ colon $=$ colon at $4 \mathrm{wk}$.

We next tried to identify the genera that contributed most to the observed differences between calves at 2 and 4 wk of age and between colon and rumen. To that end, we conducted SIMPER analysis. Table 3 lists the most influential genera in differentiating the 2 age groups in terms of abundance. Also indicated is the anatomical location, the average abundance in each age group, and the proportion they contributed to the dissimilarity between 2- and 4-wk old calves. Just 14 genera, which represented $\sim 3.6 \%$ of the total 393 genera identified, accounted for $60 \%$ of the bacterial compositional difference between 2 and 4 wk of age (Table 3). For instance, Lactobacillus, Streptococcus, and Faecalibacterium in the colon contributed about 17, 4, and 4\%, respectively, whereas Bacteroides and Oscillospira in rumen contributed about 5 and $4 \%$ each to the overall dissimilarity between 2- and 4-wk-old calves. We observed a remarkable increase of the colonic Lactobacillus population, from $\sim 34$ to $69 \%$, and a reduction of Streptococcus genus, from $\sim 12$ to $4 \%$, in the time course between 2 and 4 wk. In the rumen during the same time, Bacteroides and Porphyromonas populations dropped from $\sim 14$ to $3 \%$ and from $\sim 9.5$ to $0.7 \%$, respectively.

Regarding GI sites (Table 4), only 7 out of 393 genera identified (approximately 1.7\% of the total) accounted for $60 \%$ of the compositional difference between rumen and colon. Table 4 indicates that Lactobacillus was by far the main contributor to the abundance differences between colon and rumen, being $\sim 50 \%$ more abundant in the hindgut and adding $28 \%$ of the total dissimilarity. Streptococcus, Faecalibacterium, Clostridium, Ruminococcus, Oscillospira, and Bacteroides determined the remaining $32 \%$ dissimilarity in bacterial community composition across GI sites. Thus, not only did these 7 genera account for $60 \%$ of the abundance difference between rumen and colon, their population size also changed so drastically from 2 to 4 wk of age that they explained up to $\sim 46 \%$ of the dissimilarity between the 2 age groups (Tables 3 and 4 ).

Table 5 shows results for univariate tests complementary to SIMPER results for those genera whose additive dissimilarity contributions between age and GI site groups add to 49 (Table 3) and 60\% (Table $4)$, respectively. Lactobacillus $(P<0.0001)$ and Streptococcus $(P<0.0001)$ were greater in colon than in rumen, whereas Oscillospira $(P=0.002)$, Bacteroides $(P<0.0001)$, and Porphyromonas $(P<0.0001)$ were in greater numbers in rumen than in colon. Unlike Lactobacillus, which increased by 2.7 fold in colon from wk 2 to 4 , all other genera statistically remained at the same abundance or diminished. No statistical effect of age or GI site was observed for Faecalibacterium, Oscillospira, Clostridium, or Ruminococcus (Table 5; P>0.05).

Indicator species analysis indicated that although only 3 genera were highly specific to the colon $(P>$ 0.01 ), about 9 genera were highly specific to the rumen. Lactobacillus (0.96), Streptococcus (0.86), and Bifidobacterium (0.83) had an extremely high affinity for the colon; whereas, Actinomyces (0.94), Prevotella 
(0.91), and Eubacterium (0.9) were highly specific for the rumen $(P>0.01)$.

\section{SCFA Concentrations}

Concentrations of SCFA were measured as a proxy for microbial metabolic activity in each GI site at 2 and
4 wk of age (Table 6). Except for acetate and isovalerate, all other SCFA presented higher concentrations in the colon than in the rumen $(P<0.05)$. Propionate, isobutyrate, butyrate, and lactate were on average about 1.5, 4.4, 5.2, and 8.5 fold higher, respectively, in colon than in rumen, suggesting that some specific organisms participating in the synthesis and use of
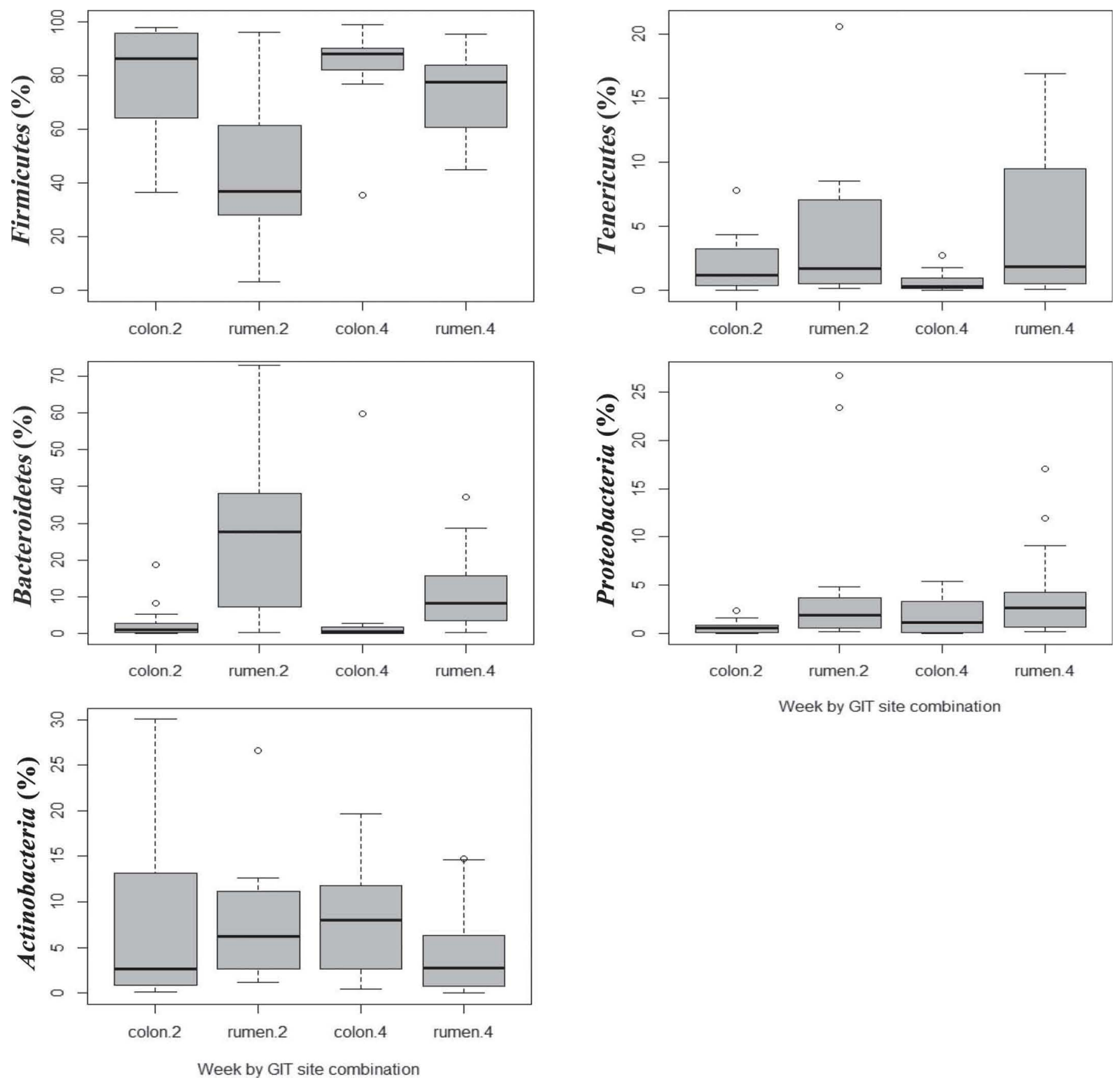

Figure 3. Distribution of predominant phyla across calf ages and gastrointestinal tract (GIT) sites. colon. $2=$ colon at 2 wk; rumen. $2=$ rumen at $2 \mathrm{wk}$; colon. $4=$ colon at $4 \mathrm{wk}$; rumen. $4=$ rumen at $4 \mathrm{wk}$. Lower and upper most bars are maximum and minimum values, respectively, excluding outliers; upper and lower box sides are 25 th and 75 th percentiles and the solid horizontal line is the median or 50 th percentile. 
Table 2. Regression coefficients for effects of calf age and gastrointestinal site on abundance of predominant phyla

\begin{tabular}{|c|c|c|c|c|}
\hline Phylum & Coefficient $(\beta)$ & $\mathrm{SE}$ & $P$-value & $\exp ^{(\beta) 1}$ \\
\hline \multicolumn{5}{|l|}{ Firmicutes } \\
\hline Intercept & -0.36 & 0.08 & 0.0001 & 0.69 \\
\hline Week 4 & 0.313 & 0.09 & 0.0022 & 1.36 \\
\hline Rumen & -0.38 & 0.08 & 0.0001 & 0.68 \\
\hline \multicolumn{5}{|c|}{ Bacteroidetes } \\
\hline Intercept & -3.17 & 0.51 & $<0.0001$ & 0.042 \\
\hline Week 4 & -0.21 & 0.59 & 0.7 & \\
\hline Rumen & 1.63 & 0.59 & 0.01 & 5.1 \\
\hline \multicolumn{5}{|c|}{ Actinobacteria } \\
\hline Intercept & -2.19 & 0.23 & $<0.0001$ & 0.11 \\
\hline Week 4 & -0.51 & 0.28 & 0.08 & \\
\hline Rumen & -0.40 & 0.28 & 0.15 & \\
\hline \multicolumn{5}{|l|}{ Tenericutes } \\
\hline Intercept & -3.32 & 0.4 & $<0.001$ & 0.0362 \\
\hline Week 4 & -1.31 & 1.39 & 0.01 & 0.27 \\
\hline Rumen & 1.39 & 0.5 & 0.01 & 4.01 \\
\hline \multicolumn{5}{|c|}{ Proteobacteria } \\
\hline Intercept & -4.60 & 0.35 & $<0.0001$ & 0.01 \\
\hline Week 4 & 0.06 & 0.44 & 0.9 & \\
\hline Rumen & 1.0 & 0.30 & 0.002 & 2.71 \\
\hline
\end{tabular}

those SCFA are much more metabolically active in the hindgut of milk-fed preruminant calves. Total SCFA did not differ between rumen and colon. These differences did not depend on age; in fact, calf age had no effect at all on SCFA concentrations. It is important to remember that different molar concentrations could have been the result of different water volumes in rumen and colon and not necessarily representative of a more active fermentation in hind gut. When SCFA concentrations were expressed as a proportion of total SCFA, acetate made up $82 \pm 2 \%$ of total SCFA in the rumen compared with $78 \pm 2 \%$ in the colon $(P<0.05)$. In contrast, butyrate constituted about $5.3 \pm 1.2 \%$ of the total SCFA in colon, but only $1.1 \pm 0.5 \%$ in rumen $(P<0.05$, Table 6$)$. Molar proportions of all other SCFA were similar in both sites.

\section{DISCUSSION}

Using a diversity index that accounts for the evenness among the various organisms inhabiting the intestinal bacterial community indicated that both rumen and colon were equally diverse at 2 and 4 wk of age. A remarkable observation was the significantly greater homogeneity of the colonic bacterial composition among calves by wk 4 . Why and how greater colonic bacterial stability develops poses an interesting unanswered question. This characteristic has been observed in the rumen of calves fed starter previously by Jami et al. (2013); in their study, similarity between calves increased in an age-dependent fashion to plateau by 6 mo of age. In the present work, however, the ruminal bacterial community remained more heterogeneous among calves at $4 \mathrm{wk}$ of age, likely due to the absence of fermentation substrate for the bacterial community to develop and structure.

In this work we also observed Firmicutes and Actinobacteria as the most abundant phyla in the calf hindgut, making up $>90 \%$ of the whole bacterial community, whereas Firmicutes and Bacteroidetes dominated in the rumen by accounting for $\sim 80 \%$. At the genus level, the calf colon at 2 wk of age was characterized by large numbers of Lactobacillus ( $\sim 34 \%)$, Streptococcus $(\sim 12 \%)$, Faecalibacterium ( 9\%), Enterococcus ( $6 \%)$, and Collinsella ( $\sim 5 \%)$. Two weeks later, Lactobacillus increased its primacy to approximately $69 \%$, and, along with Streptococcus (4\%) and Collinsella (5\%), remained most dominant in the colon, comprising $\sim 78 \%$ of the bacterial population. In addition, Lactobacillus, Streptococcus, and Bifidobacterium were found to be an almost unique bacterial assemblage feature of the colon.

In contrast, the rumen underwent many more compositional changes from wk 2 to 4 of age and no dominance by a particular genus was observed. At $2 \mathrm{wk}$ of age, Bacteroides, Oscillospira, Porphyromonas, and Bulleidia were characteristically abundant at about 14, 12, 9, and $7 \%$ of the population, respectively. By 4 wk, Oscillospira and Faecalibacterum became the 
a)

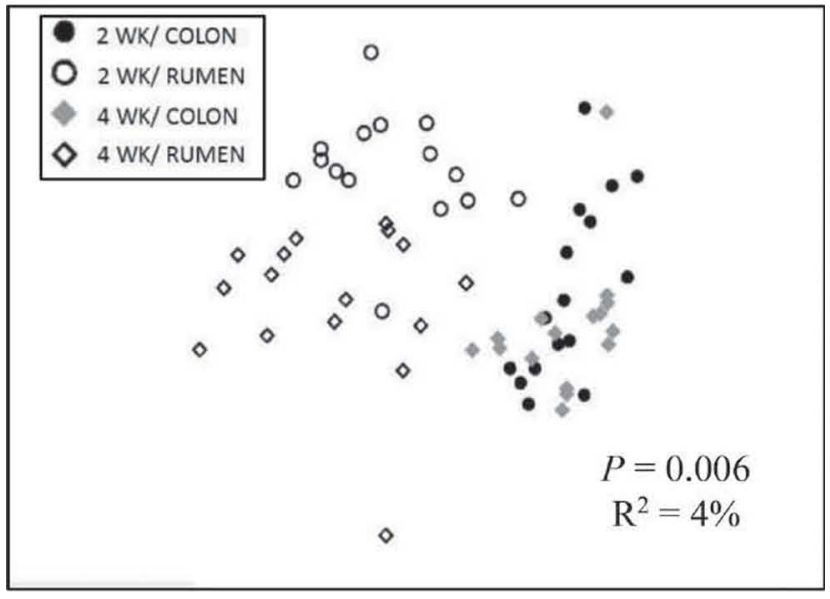

b)

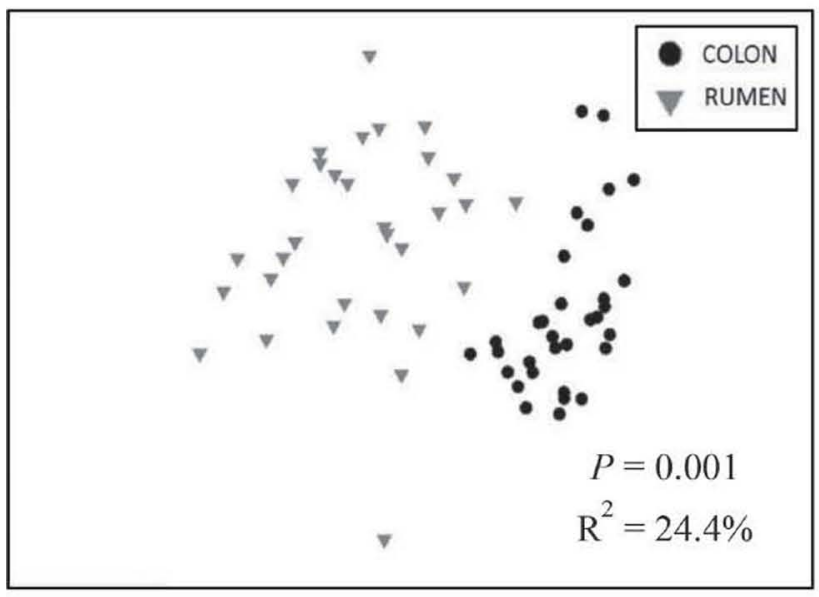

c)

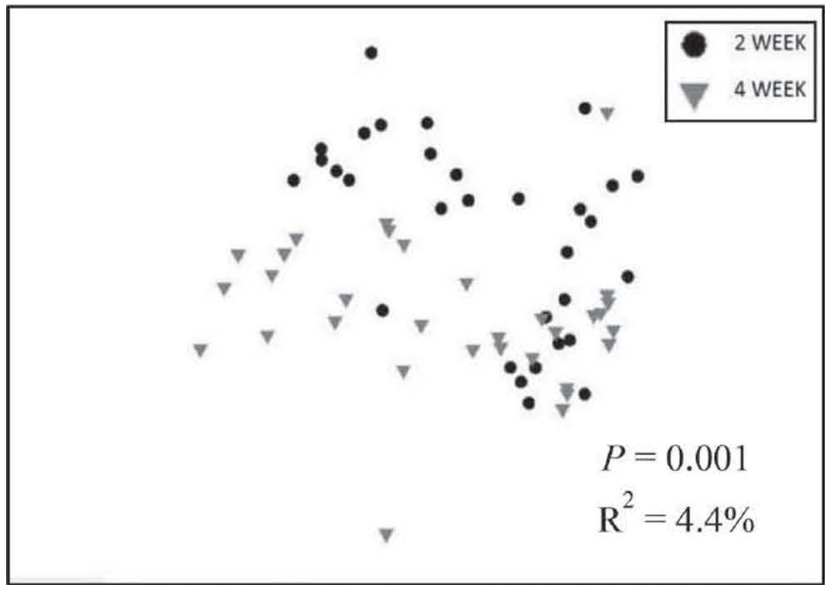

Figure 4. Nonmetric multidimensional scaling ordination of observations among calf age and gastrointestinal (GI) site groups based on taxa relative abundance and PERMANOVA (Anderson, 2001) significance tests. (a) Interaction of calf age and GI site; (b) main GI site effect; and (c) main calf age effect. most abundant taxa by increasing to approximately 16 and $10 \%$, correspondingly, whereas the others declined sharply. At the same time, other genera, such as Ruminococcus, Clostridium, and Eubacteria, increased to be in the range of 4 to $8 \%$. However, unlike in the colon, these genera together barely dominated, accounting for only $46 \%$ of the whole community.

The smaller compositional changes and the consolidation of the initially dominating bacteria in the colon suggests greater colonization resistance by lactic acid bacteria (Macfarlane et al., 2008) compared with rumen, where no truly dominant taxa were observed and many more compositional changes occurred from wk 2 to 4 . Our data indicate that colonic populations stabilized earlier than those in rumen (Rolfe, 1996).

Moreover, our findings differ with some previous observations in pre-weaned calves fed milk or milk plus starter grain where the phyla Bacteroidetes predominated over Firmicutes and the genera Bacteroides and Prevotella consistently made up the majority of the population in colonic and fecal samples at ages between 1 and 6 wk of life (Edrington et al., 2012; Li et al., 2012; Jami et al., 2013; Malmuthuge et al., 2014). A possible explanation could be that we fed no starter grain and used an intensified milk replacer feeding program with feeding rates of $2 \%$ of $\mathrm{BW}$ as DM. This translates to a dietary DM supply of $\sim 1 \mathrm{~kg} / \mathrm{d}$ for a $45-\mathrm{kg}$ BW calf. Assuming ileal apparent digestibility of DM for an average milk-based milk replacer to be at least $\sim 90 \%$ (range 80 to 92; Guilloteau et al., 1986; Khorasani et al., 1989; Petit et al., 1989; Montagne et al., 2001), an actual average dietary concentration of $28 \%$ protein and $43 \%$ lactose, and each nutrient fraction to be at least $90 \%$ digestible, at least $28 \mathrm{~g}$ of protein and $43 \mathrm{~g}$ of lactose could have passed undigested into the cecum and colon on a daily basis. In contrast, because the reticular groove is fully functional in newborn milk-fed calves (Orskov, 1992; Davis and Drackley, 1998), milk flow into the rumen, and hence provision of any fermentable substrate into it, might not exceed $10 \mathrm{~g} / \mathrm{d}$ (Toullec and Guiloteau, 1989).

Because representative species in the Lactobacillus, Streptococcus, Enterococcus, and Bifidobacterium genera are known to grow well or be able to adapt and perform well with lactose or galactose as a substrate (Özen and Özilgen, 1992; Burgos-Rubio et al., 2000; Cabral et al., 2007), and are considered major lactic acid-producing bacteria (Smith and Sherman, 1942; Macfarlane et al., 2008), we speculated that colonic supply of endogenous or milk lactose-derived di- or monosaccharides led to their overabundance and the resulting concentrations of lactate approximately 8.5 times higher in the hindgut than in the rumen. Accordingly, such high colonic acid molarities might have 
Table 3. Similarity percentage (SIMPER) analysis; contribution by specific genera to overall dissimilarity between the microbial community of calves at 2 or 4 wk of age

\begin{tabular}{llrrr}
\hline & & \multicolumn{2}{c}{ Average abundance (\%) } & \\
\cline { 3 - 4 } Genus & $\begin{array}{l}\text { Gastrointestinal } \\
\text { location }\end{array}$ & $2 \mathrm{wk}$ & $4 \mathrm{wk}$ & $\begin{array}{c}\text { Dissimilarity } \\
(\%)\end{array}$ \\
\hline Lactobacillus & Colon & 33.60 & 68.90 & 17 \\
Bacteroides & Rumen & 14.40 & 3.01 & 5 \\
Oscillospira & Rumen & 12.00 & 15.90 & 4 \\
Streptococcus & Colon & 12.30 & 3.95 & 4 \\
Fecalibacterium & Colon & 8.91 & 1.15 & 3 \\
Porphyromonas & Rumen & 9.49 & 0.74 & 3 \\
Fecalibacterium & Rumen & 5.71 & 9.57 & 3 \\
Bulleidia & Rumen & 7.23 & 1.87 & 3 \\
Ruminococcus & Rumen & 2.63 & 8.27 & 3 \\
Clostridium & Rumen & 4.12 & 8.16 & 3 \\
Oscillospira & Colon & 6.89 & 2.49 & 3 \\
Eubacterium & Rumen & 3.67 & 4.24 & 3 \\
Enterococcus & Colon & 6.43 & 1.07 & 2 \\
Collinsella & Colon & 4.53 & 4.81 & 60 \\
Total & & & & \\
\hline
\end{tabular}

caused conditions to be too acidic for bacteria such as Bacteroides spp. to grow, establish, and compete, as they prefer a $\mathrm{pH}$ of 6.5 (Belenguer et al., 2007). Indeed, low $\mathrm{pH}$ is thought to be the major mechanism by which lactic acid bacteria, primarily Lactobacillus, Bifidobacterium, and Streptococcus, inhibit growth of various facultative and anaerobic bacteria (Rolfe, 1996). Unfortunately, we did not measure luminal $\mathrm{pH}$ and hence this hypothesis remains to be tested.

Although butyrate production is not consistent with Bifidobacterium and Lactobacillus metabolism (Macfarlane et al., 2008), it has been shown that propionate producing species such as Veillonella spp. and Megasphaera elsdenii, and butyrate-producing species such as Anaerostipes caccae and Eubacterium hallii, can cross-feed on lactate produced by Bifidobacterium adolescentis (De Vuyst and Leroy, 2011). Therefore, some of the increased colonic butyrate concentrations could possibly have been the result of extensive cross-feeding (Belenguer et al., 2006; De Vuyst and Leroy, 2011).

Table 4. Similarity percentage (SIMPER) analysis; contribution by specific genera to overall dissimilarity between the microbial community of rumen and colon

\begin{tabular}{|c|c|c|c|}
\hline \multirow[b]{2}{*}{ Item } & \multicolumn{2}{|c|}{$\begin{array}{l}\text { Average abundance } \\
\qquad(\%)\end{array}$} & \multirow{2}{*}{$\begin{array}{c}\text { Dissimilarity } \\
(\%)\end{array}$} \\
\hline & Colon & Rumen & \\
\hline Lactobacillus & 51.30 & 2.16 & 28 \\
\hline Oscillospira & 4.70 & 14.0 & 8 \\
\hline Fecalibacterium & 5.87 & 7.71 & 6 \\
\hline Bacteroides & 1.40 & 8.52 & 5 \\
\hline Clostridium & 3.86 & 6.21 & 5 \\
\hline Streptococcus & 7.73 & 1.26 & 4 \\
\hline Ruminococcus & 2.56 & 5.54 & 4 \\
\hline Total & & & 60 \\
\hline
\end{tabular}

Lactobacillus and Bifidobacterium have been linked to increased resistance to infection and diarrheal disease and stimulation of immune system activity, possibly due to the chemical composition and structure of their cell wall components. Indeed, some Lactobacillus, Bifidobacterium, and Enterococcus species form substances that are antagonistic to other organisms, such as organic acids and bacteriocins (Macfarlane et al., 2008; Vizoso Pinto et al., 2009). For example, Bifidobacterium infantis can produce substances that are inhibitory to $E$. coli and Clostridium perfringens, whereas other bifido species can inhibit Listeria, Shigella, Campylobacter, and Vibrio cholerae (Gibson and Wang, 1994). Given the high colonic abundance and specificity observed here, lactic acid bacteria and Bifidobacterium may have had a positive role in the intestinal health of calves in this study.

In addition to such direct bacterial effects, SCFA, as the major fermentation end products, also have a role in colonic function and integrity. Whereas acetate and propionate affect the epithelium's energy and the host's glucose homeostasis, respectively (Topping and Clifton, 2001), butyrate production in the hindgut can improve epithelium permeability by upregulating tight junction protein expression (Cani et al., 2009), reducing epithelium inflammation (Macfarlane et al., 2008), and promoting cell differentiation (Topping and Clifton, 2001).

From this standpoint, our observations suggest a role for the observed high lactic acid bacteria profile in newborn preruminant calves, which was reflected in this case by a comparatively greater molar proportion of butyrate and possibly higher molar concentration of lactate in colon than in the rumen. Perhaps colonic fermentation, contingent upon milk feeding rate, is 
Table 5. Regression coefficients for effect of calf age and gastrointestinal site on abundance of differentiator genera

\begin{tabular}{|c|c|c|c|c|}
\hline Genus & Coefficient $(\beta)$ & SE & $P$-value & $\exp ^{(\beta) 1}$ \\
\hline \multicolumn{5}{|c|}{ Lactobacillus } \\
\hline Intercept & -1.34 & 0.31 & $<0.0001$ & 0.26 \\
\hline Week 4 & 1.31 & 0.36 & 0.0012 & 3.7 \\
\hline Rumen & -3.52 & 0.36 & $<0.0001$ & 0.029 \\
\hline \multicolumn{5}{|l|}{ Oscillospira } \\
\hline Intercept & -3.1 & 0.33 & $<0.0001$ & 0.05 \\
\hline Week 4 & -0.32 & 0.39 & 0.42 & \\
\hline Rumen & 1.3 & 0.38 & 0.002 & 3.66 \\
\hline \multicolumn{5}{|c|}{ Fecalibacterium } \\
\hline Intercept & -3.26 & 0.50 & $<0.0001$ & 0.038 \\
\hline Week 4 & -0.29 & 0.55 & 0.60 & \\
\hline Rumen & 0.86 & 0.56 & 0.13 & \\
\hline \multicolumn{5}{|l|}{ Bacteroides } \\
\hline Intercept & -4.37 & 0.33 & $<0.0001$ & 0.012 \\
\hline Week 4 & -1.69 & 0.41 & $<0.0001$ & 0.18 \\
\hline Rumen & 2.07 & 0.29 & $<0.0001$ & 7.92 \\
\hline \multicolumn{5}{|c|}{ Streptococcus } \\
\hline Intercept & -2.26 & 0.29 & $<0.0001$ & 0.10 \\
\hline Week 4 & -0.85 & 0.34 & 0.01 & 0.42 \\
\hline Rumen & -1.71 & 0.34 & $<0.0001$ & 0.18 \\
\hline \multicolumn{5}{|c|}{ Porphyromonas } \\
\hline Intercept & -6.51 & 0.44 & $<0.0001$ & 0.001 \\
\hline Week 4 & -1.44 & 0.52 & 0.001 & 0.23 \\
\hline Rumen & 3.73 & 0.52 & $<0.0001$ & 41.6 \\
\hline \multicolumn{5}{|l|}{ Clostridium } \\
\hline Intercept & -3.76 & 0.59 & $<0.0001$ & 0.02 \\
\hline Week 4 & -0.12 & 0.62 & 0.84 & \\
\hline Rumen & 0.93 & 0.63 & 0.15 & \\
\hline \multicolumn{5}{|c|}{ Ruminococcus } \\
\hline Intercept & -4.61 & 0.70 & $<0.0001$ & 0.009 \\
\hline Week 4 & 0.49 & 0.64 & 0.45 & \\
\hline Rumen & 1.34 & 0.67 & 0.06 & 3.82 \\
\hline
\end{tabular}

Table 6. Short-chain fatty acid and lactate concentrations (mmol/L) and molar proportions (mol/100 mol) in rumen and colon at 2 and 4 wk of age

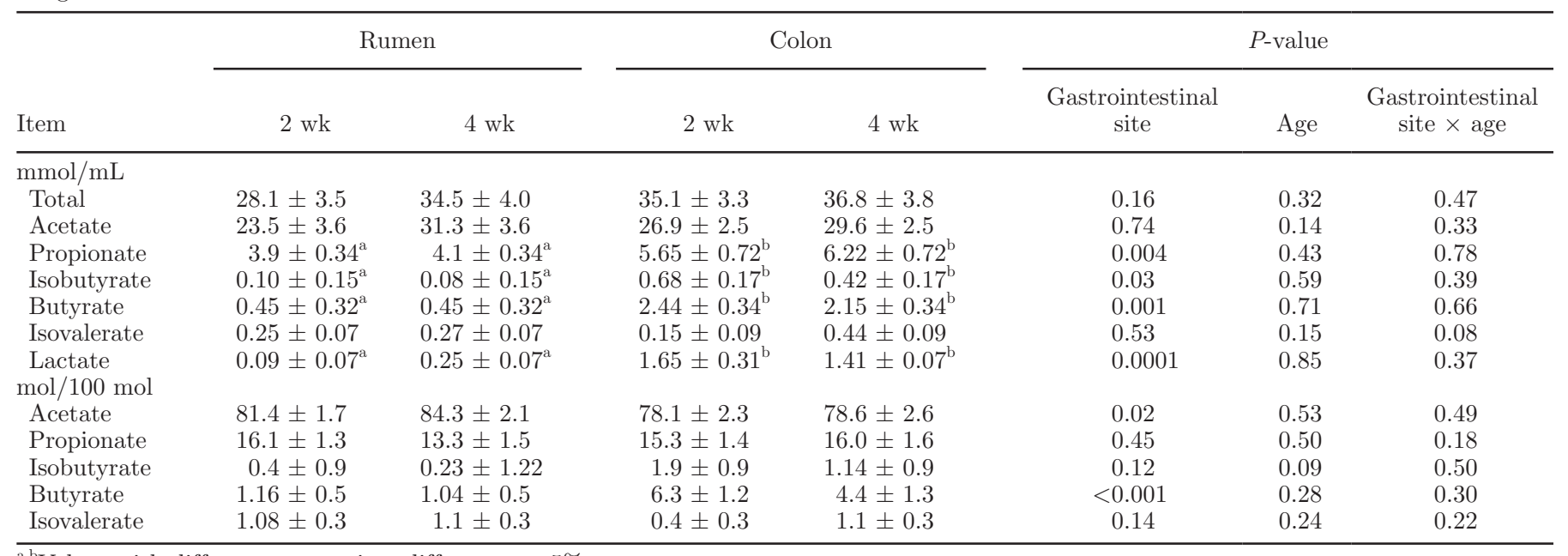

\footnotetext{
${ }^{\mathrm{a}, \mathrm{b}}$ Values with different superscripts differ at $\alpha=5 \%$.
} 
preponderant to support intestinal health and integrity during the first few weeks of life, whereas ruminal fermentation would develop and become increasingly important for the metabolic energy supply of the calf after 4 wk of life (Davis and Drackley, 1998). Our speculation is that the high milk feeding rate is a possible cause for the much more abundant LAB populations observed here compared with calves from other experiments. This notion leads us to propose that quantifying the undigested milk nutrient flow into the large intestine with increasing feeding rates, and its relationship to intestinal health and development, is a topic worthy of additional research.

\section{CONCLUSIONS}

The rumen and colon of intensively milk-fed preruminant calves had a similar number of effective bacterial species during the first month of life. The intercalf variation in colonic bacterial composition diminished significantly by 4 wk of age compared with the rumen. Lactic acid bacteria such as Lactobacillus, Streptococcus, Enterococcus, and Bifidobacterium dominated the bacterial community in the hindgut. In addition, SCFA concentrations were between 0.5 and 8.5 times higher in the colon than in the rumen. High SCFA concentrations may have inhibited the Bacteroides genus from expanding, which appears atypical in calves and other species. These bacterial community and SCFA profiles could bring about beneficial effects for the intestinal health of calves during the first 2 to 4 wk of life. On the other hand, in the rumen, no genus showed to over-dominate, and butyrate and lactate concentrations were much lower than in colon, presumably due to lack of fermentable substrate. It is reasonable to think that, because of an active reticular groove and low grain intake during the first 2 to 3 wk of life, ruminal fermentation may not take preponderance until after about 4 wk of life, when significant ME contributions to the energy budget of the calf start to take place. Research studying potential nutritional management to optimize hindgut fermentation during early life to support intestinal health should prove worthwhile.

\section{ACKNOWLEDGMENTS}

The authors greatly appreciate the technical help of the many graduate and undergraduate students in the Department of Animal Sciences (University of Illinois) in care of calves, sampling, and harvest processing of calves. Partial financial support and milk replacer manufacturing was provided by Milk Specialties Global Animal Nutrition (Eden Prairie, MN). The authors thank Land O'Lakes Animal Milk Co. (Arden Hills, $\mathrm{MN}$ ) for donation of the electrolyte product.

\section{REFERENCES}

Anderson, M. J. 2001. A new method for non-parametric multivariate analysis of variance. Austral Ecol. 26:32-46.

Anderson, M. J. 2006. Distance-based tests for homogeneity of multivariate dispersions. Biometrics 62:245-253.

Anderson, M. J., and D. C. I. Walsh. 2013. PERMANOVA, ANOSIM, and the mantel test in the face of heterogeneous dispersions: What null hypothesis are you testing? Ecol. Monogr. 83:557-574.

Beever, D. E., and F. L. Mould. 2000. Forage evaluation for efficient ruminant livestock production. Pages 15 in Forage Evaluation in Ruminant Nutrition. D. I. Givens, E. Owen, R. F. E. Axford, and H. M. Omed, ed. CAB International, Wallingford, UK.

Belenguer, A., S. H. Duncan, A. G. Calder, G. Holtrop, P. Louis, G. E. Lobley, and H. J. Flint. 2006. Two routes of metabolic crossfeeding between Bifidobacterium adolescentis and butyrate-producing anaerobes from the human gut. Appl. Environ. Microbiol. 72:3593-3599.

Belenguer, A., S. H. Duncan, G. Holtrop, S. E. Anderson, G. E. Lobley, and H. J. Flint. 2007. Impact of $\mathrm{pH}$ on lactate formation and utilization by human fecal microbial communities. Appl. Environ. Microbiol. 73:6526-6533.

Bolker, B. M., M. E. Brooks, C. J. Clark, S. W. Geange, J. R. Poulsen, M. H. Stevens, and J. S. White. 2009. Generalized linear mixed models: A practical guide for ecology and evolution. Trends Ecol. Evol. 24:127-135. (Abstr.).

Borcard, D., F. Gillet, and P. Legendre. 2011. Numerical Ecology with R. 1st ed. Springer, New York, NY.

Burgos-Rubio, C. N., M. R. Okos, and P. C. Wankat. 2000. Kinetic study of the conversion of different substrates to lactic acid using Lactobacillus bulgaricus. Biotechnol. Prog. 16:305-314.

Butler, D. G., and R. C. Clarke. 1994. Diarrhea and dysentery in calves. Page 91 in Escherichia coli in Domestic Animals and $\mathrm{Hu}-$ mans. C. L. Gyles ed. CAB International, Wallingford, UK.

Cabral, M. E., M. C. Abeijón Mukdsi, R. Medina de Figueroa, and S. González. 2007. Citrate metabolism by Enterococcus faecium and Enterococcus durans isolated from goat's and ewe's milk: Influence of glucose and lactose. Can. J. Microbiol. 53:607-615.

Cani, P. D., S. Possemiers, T. Van de Wiele, Y. Guiot, A. Everard, O. Rottier, L. Geurts, D. Naslain, A. M. Neyrinck, D. M. Lambert, G. G. Muccioli, and N. M. Delzenne. 2009. Changes in gut microbiota control inflammation in obese mice through a mechanism involving GLP-2-driven improvement of gut permeability. Gut 58:1091-1103.

Castro, J. J., A. Gomez, B. A. White, H. J. Mangian, J. R. Loften, and J. K. Drackley. 2016. Changes in the intestinal bacterial community, short chain fatty acid profile, and intestinal development of pre-weaned Holstein calves. 1. Effects of prebiotic supplementation depend on site and age. J. Dairy Sci. 99:9682-9702 http://dx.doi. org/10.316/jds.2016-11006.

Clarke, K. R. 1993. Non-parametric multivariate analyses of changes in community structure. Aust. J. Ecol. 18:117-143.

Clarke, K. R. and R. N. Gorley. 2006. PRIMER v6. Massey University, Auckland, New Zealand.

Davis, C. L., and J. K. Drackley. 1998. The Development, Nutrition, and Management of the Young Calf. 1st ed. Iowa State Univ. Press, Ames, IA.

De Vuyst, L., and F. Leroy. 2011. Cross-feeding between bifidobacteria and butyrate-producing colon bacteria explains bifdobacterial competitiveness, butyrate production, and gas production. Int. J. Food Microbiol. 149:73-80.

Dowd, S. E., T. Callaway, R. Wolcott, Y. Sun, T. McKeehan, R. Hagevoort, and T. Edrington. 2008b. Evaluation of the bacterial diversity in the feces of cattle using $16 \mathrm{~S}$ rDNA bacterial tag-encoded FLX amplicon pyrosequencing (bTEFAP). BMC Microbiol. 8:125.

Dowd, S. E., Y. Sun, R. D. Wolcott, A. Domingo, and J. A. Carroll. 2008a. Bacterial tag-encoded FLX amplicon pyrosequencing (bTE- 
FAP) for microbiome studies: Bacterial diversity in the ileum of newly weaned Salmonella-infected pigs. Foodborne Pathog. Dis. 5:459-472.

Dufrene, M., and P. Legendre. 1997. Species assemblages and indicator species: The need for a flexible asymetrical approach. Ecol. Monogr. 67:345-366.

Edrington, T. S., S. E. Dowd, R. F. Farrow, G. R. Hagevoort, T. R. Callaway, R. C. Anderson, and D. J. Nisbet. 2012. Development of colonic microflora as assessed by pyrosequencing in dairy calves fed waste milk. J. Dairy Sci. 95:4519-4525.

Fitzmaurice, G. M., N. M. Laird, and J. H. Ware, eds. 2011. Applied Longitudinal Analysis. 2nd ed. John Wiley \& Sons, Hoboken, NJ.

Flatt, W. P., R. G. Warner, and J. K. Loosli. 1958. Influence of purified materials on the development of the ruminant stomach. J. Dairy Sci. 41:1593-1600.

Gibson, G. R., and X. Wang. 1994. Regulatory effects of Bifidobacteria on the growth of other colonic bacteria. J. Appl. Bacteriol. $77: 412-420$.

Guilloteau, P., R. Toullec, J. Grongnet, P. Patureau-Mirand, J. Prugnaud, and D. Sauvant. 1986. Digestion of milk, fish and soya-bean protein in the preruminant calf: Flow of digesta, apparent digestibility at the end of the ileum and amino acid composition of ileal digesta. Br. J. Nutr. 55:571-592.

Hart, M. L., A. Meyer, P. Johnson, and A. Ericsson. 2015. Comparative evaluation of DNA extraction methods from feces of multiple host species for downstream next-generation sequencing. PLoS ONE 10:e0143334.

Herfel, T., S. Jacobi, X. Lin, E. Van Heugten, V. Fellner, and J. Odle. 2013. Stabilized rice bran improves weaning pig performance via a prebiotic mechanism. J. Anim. Sci. 91:907-913.

Hill, T. M., H. G. Bateman 2nd, J. M. Aldrich, and R. L. Schlotterbeck. 2010. Effect of milk replacer program on digestion of nutrients in dairy calves. J. Dairy Sci. 93:1105-1115.

Huber, J. T. 1969. Development of the digestive and metabolic apparatus of the calf. J. Dairy Sci. 52:1303-1315.

Izzo, M. M., P. Kirkland, V. Mohler, N. Perkins, A. Gunn, and J. House. 2011. Prevalence of major enteric pathogens in Australian dairy calves with diarrhoea. Aust. Vet. J. 89:167-173.

Jami, E., A. Israel, A. Kotser, and I. Mizrahi. 2013. Exploring the bovine rumen bacterial community from birth to adulthood. ISME J. 7:1069-1079.

Khorasani, G. R., L. Ozimek, W. C. Sauer, and J. J. Kennelly. 1989. Substitution of milk protein with isolated soy protein in calf milk replacers. J. Anim. Sci. 67:1634-1641.

Legendre, P. 2013. Indicator species: Computation. Pages 264-268 in Encyclopedia of Biodiversity. 2nd ed. S. A. Levin, ed. Academic Press, Waltham, MA.

Li, R. W., E. E. Connor, and C. Li., R. L. Baldwin VI, and M. E. Sparks. 2012. Characterization of the rumen microbiota of preruminant calves using metagenomic tools. Environ. Microbiol. 14:129-139.

Macfarlane, G. T., H. Steed, and S. Macfarlane. 2008. Bacterial metabolism and health-related effects of galacto-oligosaccharides and other prebiotics. J. Appl. Microbiol. 104:305-344.

Mackie, R. I., A. Sghir, and H. R. Gaskins. 1999. Developmental microbial ecology of the neonatal gastrointestinal tract. Am. J. Clin. Nutr. 69:1035S-1045S

Malmuthuge, N., P. J. Griebel, and L. L. Guan. 2014. Taxonomic identification of commensal bacteria associated with the mucosa and digesta throughout the gastrointestinal tract of pre-weaned calves. Appl. Environ. Microbiol. 80:2021-2028.

Montagne, L., R. Toullec, and J. P. Lalles. 2001. Intestinal digestion of dietary and endogenous proteins along the small intestine of calves fed soybean or potato. J. Anim. Sci. 79:2719-2730.

NAHMS. 2010. National Animal Health Monitoring System. Heifer Calf Health and Management Practices on U.S. Dairy Operations in 2007. USDA, Animal and Plant Health Inspection Service, Veterinary Service, Center for Epidemiology and Animal Health, Fort Collins, CO.
Oikonomou, G., A. G. V. Teixeira, C. Foditsch, M. L. Bicalho, V. S. Machado, and R. C. Bicalho. 2013. Fecal microbial diversity in pre-weaned dairy calves as described by pyrosequencing of metagenomic $16 \mathrm{~S}$ rDNA. Associations of Faecalibacterium species with health and growth. PLoS ONE 8:e63157.

Oksanen, J., F. G. Blanchet, R. Kindt, P. Legendre, P. R. Minchin, R. B. O'Hara, G. L. Simpson, P. Solymos, M. H. Stevens, and H. Wagner. 2012. Vegan: Community ecology package. R package version 2.0-5. Accessed Sep. 4, 2014. http://CRAN.R-project.org/ package $=$ vegan

Orskov, E. R. 1992. Protein Nutrition of the Ruminant. 2nd ed. Academic Press, Barking, UK.

Özen, S., and M. Özilgen. 1992. Effects of substrate concentration on growth and lactic acid production by mixed cultures of Lactobacillus bulgaricus and Streptococcus thermophilus. J. Chem. Technol. Biotechnol. 54:57-61.

Petit, H. V., M. Ivan, and G. J. Brisson. 1989. Digestibility measured by fecal and ileal collection in preruminant calves fed a clotting or a nonclotting milk replacer. J. Dairy Sci. 72:123-128.

Roberts, D. W. 2012. labdsv: Ordination and multivariate analysis for ecology. R package version 1.5-0. Accessed Apr. 9, 2014. http:// CRAN.R-project.org/package=labdsv.

Rolfe, R. D. 1996. Colonization resistance. Page 501 in Gastrointestinal Microbiology. Vol. 2. R. I. Mackie, B. A. White, and R. E. Isaacson, ed. Chapman and Hall, 1996.

Smith, P. A., and J. M. Sherman. 1942. The lactic acid fermentation of streptococci. J. Bacteriol. 43:725-731.

Stewart, C. S., G. Fonty, and P. Gouet. 1988. The establishment of rumen microbial communities. Anim. Feed Sci. Technol. 21:69-97.

Sutton, J. D., A. D. McGilliard, and N. L. Jacobson. 1963a. Functional development of rumen mucosa. I. Absorptive ability. J. Dairy Sci. 46:426-436.

Sutton, J. D., A. D. McGilliard, M. Richard, and N. L. Jacobson. 1963b. Functional development of rumen mucosa. II. Metabolic activity. J. Dairy Sci. 46:530-537.

Sweeney, B. C., J. Rushen, D. M. Weary, and A. M. de Passillé. 2010. Duration of weaning, starter intake, and weight gain of dairy calves fed large amounts of milk. J. Dairy Sci. 93:148-152.

Topping, D. L., and P. M. Clifton. 2001. Short-chain fatty acids and human colonic function: Roles of resistant starch and nonstarch polysaccharides. Physiol. Rev. 81:1031-1064.

Toullec, R., and P. Guiloteau. 1989. Research into the digestive physiology of the milk fed calf. Page 35 in Nutrition and Digestive Physiology in Monogastric Farm Animals. E. J. Van Weerdon and J. Huisman, ed. University of Wageningen, Wageningen, the Netherlands.

Tuomisto, H. 2010. A consistent terminology for quantifying species diversity? Yes, it does exist. Oecologia 164:853-860.

Venables, W. N., and B. D. Ripley. 2002. Modern Applied Statistics with S. 4th ed. Springer, New York, NY.

Vizoso Pinto, M. G., M. Rodriguez Gómez, S. Seifert, B. Watzl, W. H. Holzapfel, and C. M. A. P. Franz. 2009. Lactobacilli stimulate the innate immune response and modulate the TLR expression of HT29 intestinal epithelial cells in vitro. Int. J. Food Microbiol. 133:86-93.

Warner, R. G., and W. P. Flatt. 1965. Anatomical development of the ruminant stomach. Page 24 in Physiology of Digestion in the Ruminant. R. W. Dougherty, R. S. Allen, W. Burroughs, N. L. Jacobson, and A. D. McGilliard, ed. Butterworth, Washington, DC.

Warner, R. G., W. P. Flatt, and J. K. Loosli. 1956. Ruminant nutrition, dietary factors influencing development of ruminant stomach. J. Agric. Food Chem. 4:788-792.

Warton, D. I., S. T. Wright, and Y. Wang. 2012. Distance-based multivariate analyses confound location and dispersion effects. Methods Ecol. Evol. 3:89-101.

Zuur, A. F., E. L. Ieno, N. J. Walker, A. A. Saveliev, and G. M. Smith. 2009. Mixed Effects Models and Extensions in Ecology with R. Springer, New York, NY. 